\title{
资 \\ 政 \\ A idéia de referência: o acompanhamento terapêutico como paradigma de trabalho em um serviço de saúde mental
}

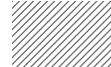

\author{
Alessandra Monachesi Ribeiro \\ Espaço Brasileiro de Estudos Psicanalíticos
}

\begin{abstract}
Resumo
Este trabalho visa explorar a idéia de que o Acompanhamento Terapêutico serve como paradigma de manejo na clínica das psicoses em instituições de saúde mental. Com base em experiência como psicóloga, psicanalista e acompanhante terapêutica em um desses serviços, o CAPS-Itapeva, faço uma reflexão sobre como essa clínica do acompanhamento é necessária no cotidiano institucional, permeando todos os espaços de tratamento. A partir da idéia de referência, segundo a qual cabe a um profissional qualquer do serviço acompanhar o percurso de determinado paciente ali, servindo de intermediário entre ele e as atividades, tanto quanto entre ele e o fora da instituição, busco problematizar os pontos em que a clínica do AT se aproxima dessa clínica institucional das psicoses.
\end{abstract}

Palavras-chave: clínica das psicoses; instituição de saúde mental; caps; acompanhamento terapêutico; manejo clínico

\begin{abstract}
The Therapeutic Accompaniment as a mental health care institution's work paradigm. This text aims to explore the idea that the Therapeutic Accompaniment can be used as a paradigm to the holding concept at the clinic of psychosis within mental health institutions. Based on my personal experience as psychologist, psychoanalyst and therapeutic accompanier at one of these institutions, named CAPS-Itapeva (Psychossocial Attention Center - Itapeva), I think on how this accompaniment clinic is necessary to the institutional routine, crossing all the treatment spaces. From the idea of reference, which stands that it's up to each professional working within the institution to accompany the route of each single patient, standing as a intermediate between him and his activities, as well as between him and what is out of there, I try to seeks where the Therapeutic Accompaniment's clinic approaches to the psychosis institutional clinic.
\end{abstract}

Keywords: clinic of the psychosis; mental health institution; caps - psychossocial attention center; therapeutic accompaniment; clinical holding

$\mathrm{C}$ omeço este texto resgatando o que é o contexto institucional sobre o qual procuro refletir através da proposta de que o trabalho de acompanhamento terapêutico (AT) seria seu paradigma. O CAPS-Itapeva Centro de Atenção Psicossocial Professor Luiz da Rocha Cerqueira - surge em 1987, no Brasil, em São Paulo, capital, fruto da influência das experiências de Reforma Psiquiátrica na Inglaterra, Itália, França e E.U.A. e da tentativa de construção de um caminho próprio que poderia, até mesmo, servir como modelo alternativo de atenção em saúde mental para outros serviços públicos (Amarante, 1998; Bezzerra Jr. \& Amarante, 1992; Desviat, 1999; Goldberg, 1998; Ribeiro, 2004; 2007). De seus antecessores, traz na bagagem as noções de que existe um sujeito a ser tratado, que não se reduz à doença, e que a forma tradicional ditada pela psiquiatria clássica produz apenas exclusão e cronificação.

A idéia de sujeito, aqui, aparece com uma conotação política. Trata-se de uma aposta de que o louco é um sujeito, no sentido de ser cidadão e, com isso, pode ter acesso aos direitos que a cidadania the proporciona. Esta aposta difere - apesar de ter com ela alguma proximidade - daquela aposta que o psicanalista faz em relação a seu paciente, a de que existe ali um sujeito capaz de saber de si, principalmente nos âmbitos em que se desconhece.

O louco não tem voz e o saber médico aliou-se ao saber jurídico para garantir que isso se traduzisse e confirmasse pela idéia de que ele deveria ser cuidado - tutelado - posto que não teria qualquer responsabilidade social devido à sua incapacidade - seria inimputável. Um louco não-cidadão, calado e segregado, serve como símbolo da intolerância às diferenças e está em 
consonância com o movimento contra a ditadura militar que se fortificou no final da década de 70 e no início da década de 80 , momento em que surgem os primeiros movimentos dos trabalhadores de saúde mental no Brasil, com propostas de reformulação do modelo assistencial, com uma visão crítica sobre o saber psiquiátrico e do qual nosso já mencionado CAPS foi um dos frutos.

Como se sabe, o campo da saúde mental teve uma participação ativa nos movimentos contra a ditadura militar desde a década de 70, sendo que a proposição mesma de modelos alternativos de atenção à saúde, que questionassem o paradigma psiquiátrico e a tradição hospitalocêntrica, constituíram-se um modo de colocar em questão a ideologia tutelar e autoritária existente durante aquele período. Além da posição questionadora presente no próprio modelo proposto pela Reforma Psiquiátrica desde então, o inegável engajamento político daqueles que fundaram esses primeiros CAPS colocaram tal modelo indissociável de uma certa ação política, de que o movimento criado por funcionários, familiares e usuários dos serviços de saúde mental dá testemunho, desde então.

A idéia de saúde como dever do Estado e direito do cidadão, a idéia de bem-estar social e de qualidade de vida surgem na década de 80 , assim como a priorização de um melhor funcionamento dos serviços públicos de saúde como um sistema único, integrado e que garantisse ao cidadão acesso universal, descentralizado e democrático. No âmbito da assistência, essa nova concepção desaguou na criação de novas modalidades de atenção, que passaram a apresentar uma alternativa real ao hospital psiquiátrico tradicional. Houve a criação de serviços alternativos e a internação como etapa no tratamento tornouse possível nas enfermarias psiquiátricas em hospitais-gerais. No entanto, os hospitais psiquiátricos não deixaram de existir como lugares de internação - quer temporária, como etapa de tratamento, quer no sentido da exclusão e do confinamento. Junto com as reformas na assistência, fez-se necessária uma articulação dos movimentos de trabalhadores, e as famílias passaram também a organizar-se no intuito de questionar e promover discussões em torno das políticas públicas de saúde, de forma que o quadro pudesse ser alterado em favor da priorização do modelo alternativo.

$\mathrm{O}$ atendimento torna-se regionalizado, territorial e há uma tentativa de que a pessoa possa ser atendida em sua comunidade e não perca as referências de seu contexto social, não se desterritorialize. Há a preocupação em garantir seu direito de cidadania, a desospitalização e a promoção da saúde mental, tanto no nível individual quanto mais amplamente.

Voltando à proposta feita pelo CAPS desde 1987, a idéia de que há um sujeito a ser tratado e não uma doença coloca-o como protagonista (o sujeito) de seu tratamento, que é pessoal, particular e intransferível. Cada qual tem, no contexto institucional, seu próprio projeto terapêutico, sua maneira singular de circulação e participação nas atividades propostas, enfim, sua inserção própria na malha institucional, a qual ajuda a criar. A equipe - multiprofissional - realiza o cuidado dos usuários do serviço (não mais pacientes) e garante a oferta do maior número de dispositivos de tratamento possível, uma vez que não se sabe ao que cada um vai se vincular e existe a firme intenção de que um usuário possa se vincular a alguma atividade ou a alguém e que daí se desenrole seu tratamento.

O projeto CAPS, que foi se ampliando ao longo dos anos e abarcando áreas cada vez mais abrangentes da vida de seus usuários, transformou seus projetos de tratamento em projetos de vida, em que a clínica transforma-se em assistência e em intervenção no que diz respeito à sociabilidade. Para essa conformação contribuiu a influência da psiquiatria democrática italiana e seus descendentes, que enfatizavam o lidar com pessoas que sofrem transtornos emocionais graves a partir da perspectiva da reabilitação psicossocial. A prioridade recairia sobre o favorecimento do poder de troca do sujeito, tanto no âmbito afetivo quanto material. Habilitar seria construir essa possibilidade de troca e negociação, sem a qual as relações ficariam engessadas e restritas à repetição constante do único lugar a partir do qual o louco pode estabelecer trocas - o lugar de doente.

$\mathrm{Na}$ perspectiva da reabilitação psicossocial, para haver um aumento do poder contratual do paciente teriam que ser contemplados os seguintes eixos de sua vida: moradia, família e trabalho. A ênfase seria dada no favorecimento da autonomia a partir da diversificação dos lugares e possibilidades de estabelecer relações.

O que se apresenta nos dias de hoje é o dispositivo CAPS como modelo e paradigma de atenção à saúde mental (Ribeiro, 2005). Utilizarei, como referência básica para apresentá-lo, o material escrito pelo Ministério da Saúde no ano de 2004, intitulado Saúde mental no SUS: os centros de atenção psicossocial. Temos, então, a difusão da técnica necessária a que uma instituição se constitua enquanto um CAPS como aquilo a que é dada uma ênfase considerável no relatório do Ministério da Saúde (2004), no momento em que já foi percorrido um longo caminho de quase vinte anos da aposta à experimentação, dessa ao estabelecimento de uma tecnologia e, por fim - o que se configura como retorno ao momento presente após esta breve retomada histórica -, ao estabelecimento do CAPS como modelo de atendimento em saúde mental. Acompanhemos alguns excertos do relatório:

um Centro de Atenção Psicossocial (CAPS) ou Núcleo de Atenção Psicossocial é um serviço de saúde aberto e comunitário do Sistema Único de Saúde (SUS). Ele é um lugar de referência e tratamento para pessoas que sofrem com transtornos mentais, psicoses, neuroses graves e demais quadros, cuja severidade e/ ou persistência justifiquem sua permanência num dispositivo de cuidado intensivo, comunitário, personalizado e promotor de vida. (MS, 2004, p. 13)

Ou seja, o dispositivo CAPS é apresentado como um lugar de referência, modelo no que tange o tratamento às psicoses e neuroses graves, no qual a idéia de um cuidado personalizado implica o paciente em uma posição ativa frente a seu tratamento. Caberá a ele, juntamente com a equipe que lhe presta cuidados e com seus familiares, decidir o contorno de seu tratamento.

O tratamento é personalizado e singularizado, tanto do ponto de vista de um único indivíduo que ali se encontre, como de um único serviço em uma dada região. A oferta de um CAPS é regionalizada e comunitária, preocupada e condizente 
com o território que contorna o serviço e, conseqüentemente, seus usuários e funcionários. Dessa forma, a proposição de um CAPS como modelo de atendimento em saúde mental será geral o suficiente para que, dentro dessa idéia, sejam passíveis de inclusão os mais diversos serviços, com suas particularidades territoriais e regionais.

Assim, o CAPS deve ser um dispositivo tão abrangente que se preste a contornar qualquer âmbito da vida de uma pessoa, de modo que cada indivíduo singular que ali se trate encontre a possibilidade de trilhar um caminho próprio em meio a uma profusão de ofertas. Além disso, ele deverá ter permeabilidade para manter uma ressonância com o seu entorno, aproveitandose do relevo desse lugar, dos contornos, das peculiaridades territoriais, das pessoas e das relações de sua região em prol da consecução de seus objetivos. Dito de outra maneira, o modelo CAPS deve ser amplo o suficiente para que nele caibam muitas propostas de tratamento de muitas singularidades distintas, bem como muitas propostas de serviços singulares, que tenham a cara do território que ocupam. O que garantirá que tantas especificidades digam respeito ao que pode ser entendido como um CAPS será a manutenção de uma postura ética bem definida em relação à saúde mental e ao tratamento do sofrimento psíquico.

Por postura ética, entendo aquilo que sustenta a idéia de CAPS desde seu princípio, suas concepções de loucura e de tratamento, pautadas tanto pelas elaborações da Reforma Psiquiátrica quanto, também, por uma aproximação com uma posição psicanalítica. Ambas partem do pressuposto ético de que o louco é um indivíduo com voz, capaz de dizer sobre si mesmo, de produzir obra (Birman, 1992), e de que sua loucura, portanto, não é doença a ser tratada e, conseqüentemente, curada, mas uma produção plena de sentidos que deve ganhar, no âmbito do sujeito, lugar de existência subjetiva e territorial, contorno, amarrações que viabilizem uma inscrição desse ser no mundo em que vive. Tratar de um louco seria, dessa maneira, criar dispositivos para que o mesmo possa ter lugar, se territorializar, estabelecer redes com o refinamento necessário para garantir algo que possamos chamar de vida.

O CAPS tornou-se um componente central para determinada política no campo da saúde mental. Em sendo assim, conquistou um lugar de existência previsto em lei. Com a leitura do relatório de 2004 do Ministério da Saúde, constatamos que o CAPS foi apropriado pelo poder do Estado enquanto uma política pública na área da saúde mental. Ou seja, sua ética e sua tecnologia tornaram-se modelos nesse campo de atendimento, bem como diretrizes a serem seguidas por outros serviços de saúde. Ambulatórios e hospitais-dia (HDs), por exemplo, transformaram-se em CAPS a partir de medidas legais e tiveram que se conformar aos seus parâmetros. Assim, todo o construto CAPS (ética, tecnologia e técnica) torna-se paradigma de uma ação política em saúde mental que busca dar fim ao modelo hospitalocêntrico de tratamento da loucura, oferecendo uma rede de cuidados (antes alternativa, agora oficial) na qual os CAPS ocupam lugar central.

De certo modo, tudo o que acontece em um CAPS pode ser entendido como terapêutico, quer sejam atividades específicas ou o simples estar lá, inserido em um meio acolhedor, em um ambiente terapêutico (Souza, 2003). Ou seja, essa instituição deve ser uma casa, uma morada, um lugar a ser habitado, ocupado, marcado por todos aqueles que ali vivem - funcionários e usuários -, pleno de histórias, de memórias e de intensidades. Deve ser um lugar, jamais um local de passagem, asséptico, impessoal, desfigurado. Para discorrer a respeito do CAPS como um lugar terapêutico, farei uso das idéias antropológicas de Marc Augé.

A idéia de lugar (Augé, 1994) é uma invenção necessária para dar conta dos acontecimentos, para interpretá-los e reconhecê-los dentro do campo de um discurso comum e delimitador de uma certa coletividade. Um coletivo se reconhece na singularidade de seu território, que é criada e garantida pela idéia de lugar, o que lhe garante, também, uma configuração identitária. $\mathrm{O}$ indivíduo pertence a determinado lugar - em termos de território e de identidade - mas sabe dessa ilusão, sabe que existe o outro e outros lugares sem que isso, contudo, interfira na construção totalizante do lugar do coletivo ao qual pertence.

O lugar é identitário, relacional e histórico. Ele delimita o conjunto de possibilidades, prescrições e proibições num contexto espacial tanto quanto social. O lugar de nascimento, o nome próprio, as relações estabelecidas como configuração de posições, a localização do lugar de um a partir do outro e a localização no tempo e na história... Tudo isso se estabelece com a noção de lugar. Itinerários, cruzamentos e centros/monumentos, tais são as formas espaciais utilizadas para a configuração do espaço social. Marcam o território, estabelecem o tempo e também a história em função dos quais cada indivíduo se situa. O corpo também se apresenta como espaço marcado, com seus itinerários, seus elementos e suas referências aos ancestrais: identidade, relação e história estão postas no lugar delimitado também pelo corpo. Espaço social e espaço individual partilham dos mesmos elementos para sua composição.

Juntamente com a definição de lugar, há a constatação da existência dos não-lugares. Trata-se de um espaço que não é um lugar antropológico, não liga lugares e que tem na provisoriedade, na perenidade e na idéia de passagem suas principais características. Os hospitais, os espaços de trânsito, os abrigos provisórios, os hotéis, os carros, as vias de deslocamento, os meios de transporte, as máquinas automáticas, os cartões de crédito, as redes de comunicação são o habitat do homem solitário, que está sempre de passagem. Distinguem-se do lugar antropológico, existencial, do sentido escrito e simbolizado que pressupõe o movimento, o percurso para que se efetue, abarcando a idéia de um trânsito de uma outra ordem, posto que dotado de sentido. São espaços descaracterizados, não-simbólicos, ocos de significação.

Para Augé (1994), o espaço do viajante é o arquétipo do não-lugar: ele passa por paisagens das quais tem visões sempre parciais, instantâneas, tornando sua posição de espectador o essencial acerca da viagem, pouco importando qual seja o cenário. Nem a identidade, nem a relação, nem a história fazem realmente sentido e a solidão é vivida como superação ou esvaziamento da individualidade. É o movimento da viagem que o seduz, movimento que se encerra em si próprio. Portanto, o não-lugar é o espaço constituído em relação a certos fins e a relação que os indivíduos mantêm com esse espaço. E da mesma 
forma que os lugares antropológicos criam um social orgânico, os não-lugares criam tensão solitária.

Mais do que o viajante, podemos considerar que cabe ao louco a freqüentação paradigmática do não-lugar. Ele o habita e é lá que ele tem sua origem. O lugar de passagem é seu espaço de errância, o qual percorre perpetuamente sem a condição de criar marcas históricas ou tempos de referência. Ou seja, o que é posto como não-lugar, espaço para fora, de passagem será tomado, na loucura, como seu ponto de partida. Para o louco, caracteriza a relação que estabelece com os espaços, mais do que os lugares ou não-lugares que possa freqüentar. Conseqüentemente, pensar em uma instituição que abarque a loucura é propor a criação de um dispositivo que sirva como lugar existencial para um sujeito, cuja problemática principal reside, justamente, na dificuldade em se territorializar.

Talvez seja importante enfatizar, neste ponto, que o lugar a que faço referência a partir de Augé (1994) não se detém a pensar no quanto de não-lugar, de apelo à alteridade e ao não-ser a construção de um lugar demanda. Quanto a isso, a psicanálise poderia bem nos informar ao considerar que para a construção de um lugar é necessária a relação e, conseqüentemente, a participação do outro naquilo em que ele nos revela desse jogo entre lugar e não-lugar. Contudo, na medida em que se trata aqui de mapear, mais do que essa construção subjetiva de um lugar de existência, os modos como a propiciação dessa condição se dá a partir da construção de um modelo de atenção em saúde mental, optarei por não deter-me nesse imbricamento entre lugar e nãolugar para a constituição subjetiva na loucura, aproveitando disso a idéia de que uma instituição de saúde mental como o CAPS propõe-se enquanto um lugar em que tal jogo pode ocorrer. Por isso, também, afirmo-a enquanto lugar e não enquanto lugar de passagem, guardando a diferença proposta e já explicitada, a partir de Augé (1994), entre os lugares existenciais e os lugares de passagem que são, na verdade, não-lugares dessubjetivantes. Isso não significa que um lugar como um CAPS seja um espaço engessado, que não possibilite ou facilite o trânsito, mas que, para que assim o faça, é necessário que seja um lugar e não um local de passagem em que nenhum acontecimento significativo pode ocorrer.

Para que haja um CAPS, então, é necessário haver uma disponibilidade de construção da instituição enquanto lugar, tanto quanto dos lugares possíveis de existência de cada indivíduo que ali se trata. Ou seja, demanda-se uma disposição ao outro, uma condição permanente de escuta e questionamento acerca de como esse outro se torna ator principal na construção de seu projeto de tratamento, o qual acompanhamos, bem como acerca de cada dispositivo criado pelo serviço em nome de tal acompanhamento. Uma disponibilidade de escuta, reflexão, crítica e criação, o que não é pouca coisa. Trata-se de uma clínica altamente complexa, que exige daqueles que nela se engajam uma disposição ética em relação a tanta complexidade: a possibilidade de sustentar a constituição do espaço de tratamento como um lugar no qual um sujeito singular pode vir a existir. E é a partir dessa compreensão daquilo que sustenta o trabalho em um serviço de saúde mental como o CAPS que percebo sua proximidade com o que sustenta a clínica do Acompanhamento Terapêutico.
O acompanhamento terapêutico existe desde a década de 80 como um modo de intervenção para os profissionais de saúde mental (Barretto, 1998; Equipe de Acompanhantes Terapêuticos do Instituto A Casa, 1991; 1997). Desde a perspectiva da Reforma Psiquiátrica, o tratamento dos psicóticos pode e deve tirar proveito dos mais diversos espaços, relações e situações para que o sujeito possa experimentar-se e incrementar suas maneiras de estar no mundo. Assim, o tratamento ganha o espaço das ruas, o contato com a cultura e suas produções, entra nas casas dos pacientes, aproveitando-se de qualquer brecha para algo novo surgir. Os acompanhantes terapêuticos tornam-se os experts dessa clínica do fora, clínica da rua, clínica do mundo. Seu trabalho consiste em estar junto de seus pacientes, fazer coisas que nunca foram feitas, superar algumas limitações, desenvolver potencialidades, garimpar autonomias, servir de modelo, estar presente. Aproveitam qualquer lugar como espaço de tratamento. Parece-me uma clínica de tentar o inédito com o objetivo de que o sujeito seja, cada vez mais, inteiro e autônomo.

O acompanhante enfoca aquilo que é vivido nos acompanhamentos, querendo que algo seja experimentado, apostando que uma maior autonomia e circulação no mundo podem influenciar uma movimentação psíquica. Ele ensina uma certa flexibilidade quanto aos cenários de tratamento. Aponta que os encontros se dão em muitos lugares e que, mesmo assim, podem ser aproveitados naquilo que se constrói com o paciente. Ensina que uma postura maleável, disponível ao outro e capaz de receber suas manifestações de maneira receptiva e tolerante é bem vinda, dado que um paciente psicótico necessita encontrar-se com uma pessoa real, com suas vivências e experiências, o que é fundamental para o tratamento, no mínimo por servir como modelo de identificação.

A angústia de fazer uma clínica ${ }^{1}$ com pouquíssimos enquadres possibilita que os acompanhantes sejam mais desprendidos de sua técnica, utilizando-a apenas na medida do necessário. $\mathrm{Na}$ verdade, a técnica parece ser criada em consonância com as exigências de cada acompanhamento, tornando-a tributária da experiência clínica, e não um conjunto rígido de regras que aprisionem acompanhante e acompanhado em um modelo a ser seguido, sem que a singularidade do que ali aconteça seja levada em consideração. Ou seja, o que o acompanhamento terapêutico parece oferecer para a clínica institucional em saúde mental-em sua proximidade com as proposições que sustentam os CAPS - é a sustentação dessa idéia de um projeto terapêutico singularizado, relativo e condizente com as necessidades de cada usuário. Um trânsito personalizado em meio aos contornos mais ou menos enrijecidos de uma instituição.

$\mathrm{Na}$ clínica do CAPS enfatiza-se, a partir de um certo momento de sua constituição, a idéia de referência. $\mathrm{O}$ serviço torna-se a referência do indivíduo que ali se trata, como já mencionado anteriormente. Ainda no relatório do Ministério da Saúde (2004), temos, em relação à equipe de profissionais:

As equipes técnicas devem organizar-se para acolher os usuários, desenvolver os projetos terapêuticos, trabalhar nas atividades de reabilitação psicossocial, compartilhar o espaço de convivência do serviço e poder equacionar problemas inesperados e outras questões que porventura demandem providên- 
cias imediatas, durante todo o período de funcionamento da unidade. (p. 27)

Ou seja, aqueles que trabalham em um CAPS devem guardar condições para abarcar, em suas funções, muito mais do que aquilo que está circunscrito por suas formações específicas. Demanda-se, nessa clínica, uma maior circulação por diversos papéis, atividades e funções, um acompanhamento - no sentido do que um AT faz - dos pacientes e do cotidiano institucional em suas muitas facetas. Versatilidade, mobilidade e a disposição para o imprevisto e para o improviso, não como se tais fossem acontecimentos extraordinários, mas considerando-se que, nessa clínica, os mesmos fazem parte do dia-a-dia.

Ao mesmo tempo, os profissionais tornam-se referência de algumas pessoas que freqüentam a instituição para pensar, juntamente com elas, seu percurso de tratamento. Cabe à equipe traçar um projeto terapêutico condizente com as necessidades de cada indivíduo, auxiliar no estabelecimento dos laços comunitários, bem como na criação de uma rede familiar e social. Ou seja, reside na criação de um contorno para cada usuário a principal tarefa da instituição.

O papel da equipe técnica é fundamental para a organização, desenvolvimento e manutenção do ambiente terapêutico. A duração da permanência dos usuários no atendimento dos CAPS depende de muitas variáveis, desde o comprometimento psíquico do usuário até o projeto terapêutico traçado, e a rede de apoio familiar e social que se pode estabelecer. O importante é saber que o CAPS não deve ser um lugar que desenvolve a dependência do usuário ao seu tratamento por toda a vida. O processo de reconstrução dos laços sociais, familiares e comunitários, que vão possibilitar a autonomia, deve ser cuidadosamente preparado e ocorrer de forma gradativa. (MS, 2004, p. 27)

No CAPS-Itapeva, durante um período considerável, fezse a experiência de que cada profissional se constituísse como referência para um número de usuários do serviço. Caberia a esse profissional específico, portanto, estabelecer com o usuário seu contrato e percurso de tratamento, mediar suas inserções, bem como se estabelecer como ponte de contato entre a instituição, a família e a comunidade. A circulação singular de cada usuário trazia, como correspondência, a circulação singularizada de cada profissional, sempre em sintonia com aqueles a quem serviria como referência, tornando a instituição - potencialmente um local cristalizado, com seus modos, relações e circulações préestabelecidos e estereotipados - em uma verdadeira rede de intervenções, contatos, potencializações e construções. Assim, durante esse período de tempo, o serviço foi tomado pela lógica e pelo modo de atuação muito característico do AT e, com isso, constituiu-se em território de circulação, uma praça de encontros, um lugar habitável, regido pelos movimentos que fizessem sentido a cada um.

A idéia de referência, em um serviço de saúde mental, provê essa lógica de circulação encarnada, na qual o sentido e a substância orientam o caminho. Aqui vemos contemplada, na maneira da organização institucional, a postura ética frente à loucura. A intervenção é pensada garantindo-se o máximo de singularização possível dentro de um serviço que, por existir, estabelece também seus contornos e limites.

Esse modo de funcionamento, aparentado ao acompanhamento terapêutico, configura-se, a meu ver, como paradigma de atendimento em saúde mental não apenas por meio da consideração de que existem acompanhantes terapêuticos que freqüentam, trabalham e, em algum momento, transitam com seus pacientes pelas instituições, ou que existem instituições em que, em algum momento, criam-se intervenções ou projetos nos quais haveria a demanda da participação de ATs. Mais do que isso, ao propô-lo como paradigma, refiro-me a um funcionamento modelar para a organização institucional como um todo, em que a ética e a técnica do AT acabam sendo orientadoras do fazer institucional, bem como de sua organização e de suas proposições, mesmo quando não pensadas ou explicitadas. A experiência com a idéia de referência no CAPS-Itapeva pareceme um bom exemplo de como isso tem ocorrido e parece-me interessante seguir com esse vislumbre adiante, a fim de perscrutar aquilo que, da clínica do AT tem se disseminado como uma influência mais ampla e abrangente no âmbito do trabalho em saúde mental.

O que é, afinal, esse dispositivo da referência, senão a nomeação de um lugar institucional para uma prática emprestada dessa lógica do acompanhamento? Por meio da organização em mini-equipes, em que cada profissional tem um número de usuários para os quais se constitui como referência e se dispõe a acompanhar os projetos de tratamento individuais, o que se conquista, no modo de funcionamento do CAPS-Itapeva, é a construção de uma metodologia que garanta os movimentos singulares em meio a uma instituição cujos contornos são cristalizados pelo simples fato de que se trata de uma instituição, de um lugar que se instituiu. Ou seja, por meio da referência, temos a legitimação do movimento e da criação possíveis dentro de um determinado serviço de saúde mental, a inserção de um percurso pessoal como parte imprescindível aos propósitos de um lugar impessoal, mas que visa à construção de pessoalidades.

O profissional que se faz referência, portanto, pode ser entendido como um acompanhante terapêutico, que também funciona como referência para a construção de um percurso pessoal de seu paciente em relação à cidade, à vida, aos outros ou ao que quer que lhe seja demandado. A referência, assim, diz respeito ao que se pode fazer intramuros, no âmbito de uma instituição. Um exemplo:

O "homem-rígido" ingressa na instituição vindo de uma outra, bem diferente. Espanta-se com seu modo de funcionamento e sua aparente desorganização. Em suas conversas comigo que já me conhecia do serviço de onde veio - faz questão de solicitar uma tabela de horários, seu contrato de participação nas atividades do CAPS, possível derivação dos dispositivos dos quais lançava mão, em épocas anteriores, para controlar o ambiente que o cercava: anotar todas as sessões em grupo, pedir atestados de comparecimento e assim por diante. Como referência do "homem-rígido", cabia a mim essa periódica construção de seu contrato, dos meios e modos de sua circulação, que ele queria sempre claras, estritas e ordenadas, sem nenhuma brecha para o inesperado. Em meio à rotina institu- 
cional, contudo, havia imprevistos e o "homem" se exasperava com atrasos e incompatibilidades, exigindo correções. Ordem era sua palavra-chave.

O grupo terapêutico acontece no mesmo horário que um outro grupo temático. O que fazer? O "homem-rígido" traz a questão durante muitas sessões, exasperado pelo modo como sua circulação lhe cria armadilhas, desorganizando sua metódica rotina. Nas reuniões de referência, começamos a pensar que, talvez, ele possa se atrasar um pouco, ou faltar alguma vez em um dos grupos para ir ao outro, ou até mesmo experimentar por um tempo ir às duas de maneira entrecortada para escolher a que mais the interesse, abrindo uma brecha para uma circulação mais maleável por seus interesses. A escala de horários se torna, aos poucos, obsoleta.

O "homem-rígido" constitui, aos poucos, uma rede de referências: atividades e pessoas aos quais se vincula. $\mathrm{O}$ contato com cada um deles se descola do contorno inicial das atividades rígidas. Um integrante de um grupo participa também de outro, e, por vezes, toma o mesmo rumo que ele a caminho de casa, um profissional pode ser encontrado no corredor, na rua, em várias atividades, em outros tempos e espaços para além daquele circunscrito pelo grupo que coordena. A circulação é fluida e imprevista. As relações transbordam os limites aos quais ficaram, a princípio, restritas. Encontros e desencontros surpreendemno constantemente, trazendo angústia e, por vezes, satisfação. Pode surgir, nesse contexto, sua apreciação pela música. O "homem-rígido" pode cantar: cordas vocais endurecidas pelo tempo ganham alguma maleabilidade, arejam-se com notas e sons novos. E ele se emociona, e sua emoção encontra um lugar suportável no âmbito da instituição, das pessoas, das atividades, das palavras e de tudo o mais que o rodeia ali.

O CAPS, nesse caso, funciona como um lugar para alguém cuja problemática reside em não ter lugar nenhum, posto que nada é permitido para além de uma abstrata ordem. O lugar se constrói de modo pessoal, pautado pelos ritmos, sentidos e possibilidades desse homem-rígido. A referência acompanha essas formações de sentido e significado, as marcas e experiências nas quais o lugar se anuncia, alinhavando-as enquanto pertinentes a um projeto de tratamento. Não se trata de alguém que apenas propõe algo ao usuário, mas que, atenta aos movimentos deste, busca dar corpo, forma e legitimidade àquilo que the permite enlaçar-se, vincular-se, existir. Se, no caso do homem-rígido, trata-se de suportar e aderir à feitura da grade de atividades, a princípio, trata-se, também, de atentar para os conflitos que essa grade proporciona, para a desconstrução da mesma e para a instauração de uma condição de circulação mais livre. Outro exemplo:

A "mulher-que-some" não fala, não se mexe e não adere, mesmo com todos os nossos esforços, a nenhuma atividade que lhe seja proposta. Nada. Todos os dias na instituição escorrem pelos dedos como areia, resultando em nada: nenhum vínculo, nenhum interesse, nenhum movimento, nenhum sentido. Fica, apenas, na cozinha, quieta, até que venham lhe buscar no fim do dia.
A cozinha e alguns desenhos, eis o que temos após meses de insistência, ofertas, falas e buscas. A "mulher-que-some" nos ignora e, aos poucos, damo-nos conta de que somos nós que, talvez, a estejamos ignorando. A cozinha e alguns desenhos: temos algo. A cozinha onde ela come. E desenha. E fala até. No momento em que podemos atentar a isso, tornamos a cozinha seu projeto de tratamento, juntamente com tudo e todos que por lá circulam: estar na cozinha, desenhar, ser incluída na rotina da cozinha. Ali, a "mulher-que-some" pode, enfim, aparecer.

Hakim Bey (2001) defende a idéia de que, para que haja lugares em que se viva essa experiência de autonomia, em nossos tempos, é necessário que sejam lugares não-institucionalizados. Acontecimentos espontâneos que emergem como criação de espaços temporários em que os indivíduos podem se experimentar existindo. Penso que, em uma instituição que, por ser instituição, cristaliza seus dispositivos na exata medida em que os legitima e os institui, o movimento singular e pessoal de cada indivíduo - tão necessário em uma clínica das psicoses em que a possibilidade de existência singular se coloca como problemática principal - é garantido pelos percursos de tratamento. A idéia de referência busca nomear essa possibilidade. E a tomada do acompanhamento terapêutico como paradigma dessa movimentação pelos meandros institucionais serve para pensar nessa lógica do AT como norteadora da sustentação desse lugar de referência que, por sua vez, sustenta o movimento singular do paciente, ajudando-o a costurar um lugar próprio em meio à profusão de ofertas, relações e situações decorrentes do modo de funcionamento institucional.

A construção da mobilidade e a tentativa de nomeação disso como projeto pessoal de tratamento acompanhado por uma referência são aspectos dissonantes da dinâmica institucional, uma vez que tal nomeação, na medida em que legitima, dá lugar e constrói um saber fazer a respeito disso traz, também, a possibilidade da cristalização do projeto pessoal como mais um engessamento daquilo que havia se proposto como criação de lugar de existência. Esse é um risco da institucionalização da idéia de referência e de projeto pessoal de tratamento nos CAPS. Ao mesmo tempo, a idéia do acompanhamento terapêutico como paradigma para esse modo de constituição do lugar de tratamento traz, com sua posição ética, a preocupação de que percursos guardem sentido e significação para aqueles que os fazem. Assim, a aproximação da referência e do projeto pessoal com a clínica e a experiência do AT busca desburocratizar esse modo de intervenção, precavendo-o de uma estagnação em soluções de antemão, independentes de considerações à pessoalidade daquele que ali está em tratamento.

\section{Referências}

Amarante, P. (Org.). (1998). Loucos pela vida - A trajetória da Reforma Psiquiátrica no Brasil. Rio de Janeiro: Editora Fiocruz.

Augé, M. (1994). Não-lugares - Introdução a uma antropologia da supermodernidade. Campinas: Papirus.

Barretto, K. D. (1998). Ética e técnica no acompanhamento terapêutico: andanças com Dom Quixote e Sancho Pança. São Paulo: Unimarco. 
Bey, H. (2001). Zona Autônoma Temporária. São Paulo: Conrad.

Bezerra, Jr., B., \& Amarante, P. (Orgs.). (1992). Psiquiatria sem hospício contribuições ao estudo da reforma psiquiátrica. Rio de Janeiro: RelumeDumará.

Birman, J. (1992). A cidadania tresloucada - notas introdutórias sobre a cidadania dos doentes mentais. In B. Bezerra Jr. \& P. Amarante (Orgs.), Psiquiatria sem hospício - contribuições ao estudo da reforma psiquiátrica (pp.71-90). Rio de Janeiro: Relume-Dumará.

Desviat, M. (1999). A reforma psiquiátrica. Rio de Janeiro: Editora Fiocruz.

Equipe de Acompanhantes Terapêuticos do Instituto A Casa (Orgs.). (1991). A rua como espaço clínico: acompanhamento terapêutico. São Paulo: Escuta.

Equipe de Acompanhantes Terapêuticos do Instituto A Casa (Orgs.). (1997). Crise e cidade: acompanhamento terapêutico. São Paulo: EDUC.

Goldberg, J. I. (1998). Cotidiano e instituição: revendo o tratamento de pessoas com transtorno mental em instituições públicas. Tese de doutorado não- publicada, Faculdade de Medicina da Universidade de São Paulo, São Paulo.

Ministério da Saúde. (2004). Saúde mental no SUS: os centros de atenção psicossocial. Ministério da Saúde. Secretaria de atenção à saúde, Departamento de ações programáticas estratégicas, Brasília: Autor.

Ribeiro, A. M. (2004). Em busca de um lugar: itinerário de uma analista pela clínica das psicoses. Dissertação de mestrado, Pontifícia Universidade Católica de São Paulo, São Paulo.

Ribeiro, A. M. (2005). Uma reflexão psicanalítica acerca dos CAPS: alguns aspectos éticos, técnicos e políticos. Revista Psicologia USP, 16(4), 23-56.

Ribeiro, A. M. (2007). Em busca de um lugar: itinerário de uma psicanalista pela clínica das psicoses. São Paulo: Via Lettera.

Souza, A. M. O. (2003). Loucura em cena: a 'ambiência' como espaço informal de tratamento em um centro de atenção psicossocial. Dissertação de mestrado não-publicada, Instituto de Psicologia da Universidade de São Paulo, São Paulo.

1. A idéia de clínica, no presente artigo, é usada por referência à clínica das psicoses, como é nomeada a prática que se faz em relação aos sujeitos psicóticos nesses serviços de saúde mental tais quais os CAPS, de maneira geral.

Alessandra Monachesi Ribeiro, psicanalista e mestre em psicologia clínica pelo Programa de Pós-graduação em Psicologia Clínica da Pontifícia Universidade Católica de São Paulo, é doutoranda em teoria psicanalítica pelo Programa de Pós-graduação em Teoria Psicanalitica da Universidade Federal do Rio de Janeiro (UFRJ) e membro do Espaço Brasileiro de Estudos Psicanalíticos de São Paulo e do Departamento de Psicanálise do Instituto Sedes Sapientiae. Endereço para correspondência: Rua Mario Amaral, 343; São Paulo, SP; CEP:04002-021; Tel.: (11) 3885-8755. E-mail: alemonachesi@gmail.com 